\title{
Fieser Würgegriff
}

\section{Pfifferling im Darm gefangen}

\author{
Eine Überraschung erlebten die behandelnden Ärzte im Darm \\ einer 48-jährigen Frau: Schuld an den intermittierenden \\ Bauchschmerzen der Patientin war offenbar ein Pilz gewesen, \\ den die Mediziner aus dem Zwölffingerdarm zogen.
}

Seit über vier Wochen schon hatte die schlanke Frau über krampfartige Schmerzen im Oberbauch geklagt. Von internistischen Erkrankungen war sie bis dahin immer verschont geblieben, allerdings hatte man ihr die Gallenblase entfernt und auch eine Aufrichtungsoperation wegen einer Kyphoskoliose hatte sie vor mehreren Jahren über sich ergehen lassen.

Bei der Klinikaufnahme präsentierte sich die Frau Prof. Dr. Heinrich-Josef Lübke und seinem Kollegen in einem guten Allgemeinzustand. Eine Endoskopie sollte Aufschluss über ihre Beschwerden geben. Und siehe da, im Zwölffingerdarm wurden die Ärzte fündig. Aus der Pars horizontalis duodeni entfernten sie einen Pfifferling (• Abb. 1).

Aber warum war der Pilz steckengeblieben? Die Antwort lag in der Anatomie eines Gefäßabgangs, der über der Darmpassage mündet ( $\bullet$ Abb. 2). Im beschriebenen Fall war der Winkel zwischen der Arteria mesenterica superior und der Aorta abdominalis zu gering und eine Stenose des Darms die Folge. In dieser hatte sich der Pfifferling verfangen und den Durchgang noch weiter verschlossen.

\section{Spätfolgen der \\ Aufrichtungsoperation}

Ein zu geringer Arterienabstand tritt nach Skolioseoperationen mit einer Prävalenz von $0,5-2,4 \%$ auf. Aber auch in der Normalbevölkerung kommt er vor
$(0,013-0,3 \%)$. In der Regel liegt der Winkel zwischen den beiden Arterien bei $38-56^{\circ}$. Auf der Höhe der Pars horizontalis duodeni misst der Abstand dann zwischen 10-28 mm. Liegt der Winkel aber unter $22-25^{\circ}$, ist ein Arteria-mesenterica-superior-(AMS-)Kompressionssyndrom wahrscheinlich.

\section{Mehr essen: Kalorien gegen die Kompression}

Um die Symptome des AMS-Kompressionssyndroms kurzfristig zu lindern, bietet sich die Linksseitenlage oder Knie-Brust-Position an. Um aber langfristig Beschwerden zu vermeiden, sollten betroffenen Personen ihren BodyMass-Index erhöhen, da dieser mit dem Arterienabstand korreliert. So kann eine hochkalorische Ernährung, bei der das retroperitoneale Fettgewebe zunimmt,

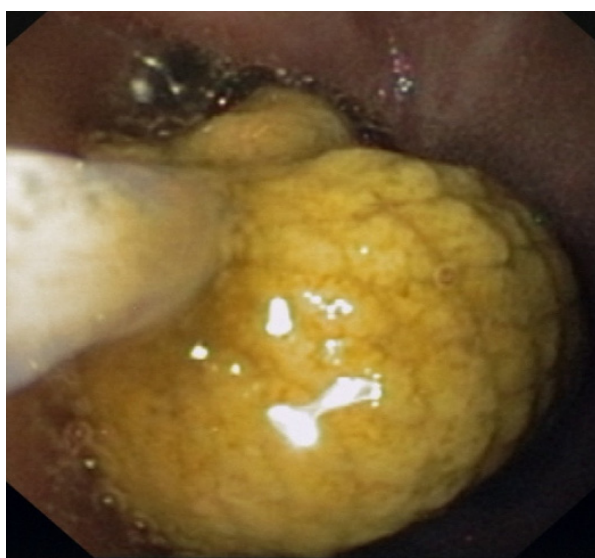

Abb. 1: In situ und nach Extraktion - der Übeltäter ist gefasst.

den aortomesenterialen Winkel vergrößern. Neben der konservativen Behandlung kommen auch chirurgische Eingriffe infrage. Möglich sind ein Durchtrennen des Treitz-Bandes oder eine Gastro- oder Duodenojejunostomie.

Im Fall des Pfifferlings zeigte sich die Patientin nach der Extraktion beschwerdefrei und der Nahrungschymus konnte den Zwölffingerdarm wieder problemlos passieren.

Gastroenterologe 2010, 5:452
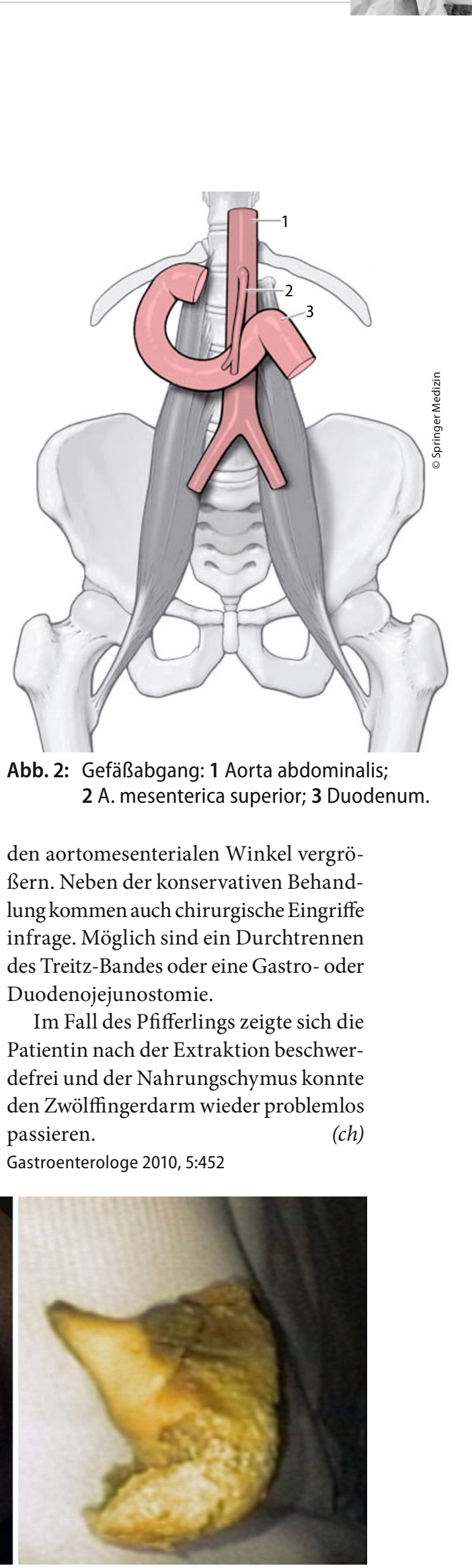

Abb. 2: Gefäßabgang: 1 Aorta abdominalis; 2 A. mesenterica superior; 3 Duodenum. 